\title{
COMPOSTELA E EUROPA. A HISTORIA DE DIEGO XELMÍREZ
}

\author{
Ana Hernández Ferreirós* \\ Universidade de Santiago de Compostela
}

EXPOSICIÓN: París (Cité de l'architecture et du Patrimoine - Musée des Monuments français), 16 de marzo al 16 de abril; Ciudad del Vaticano (Braccio di Carlo Magno), 1 junio al 1 de agosto; Santiago de Compostela (Monasterio de San Martín Pinario), 25 de agosto al 15 de octubre. Organización: S.A. de Xestión do Plan Xacobeo (Xunta de Galicia). http://compostelaeuropa.xacobeo.es/ Comisario: Manuel A. Castiñeiras González.

CATÁlOGO: Manuel Castiñeiras (com.), S.A. de Xestión do Plan Xacobeo, Skira editore, Milán, 2010, 430 págs. ISBN 978-88-572-0505-2 (Skira editore); ISBN 978-84-453-4879-6 (S. A. de Xestión do Plan Xacobeo).

La celebración del año jacobeo representa una ocasión idónea para reunir esta muestra en la que se elogia el carácter internacional de la sede compostelana y se revelan las razones por las que Santiago se estableció como el gran centro de recepción de peregrinos que hoy en día continua siendo. Existen múltiples posibilidades en cuanto al concepto central en torno al que pivota cualquier exposición pero la elección de una trayectoria vital, de la biografía de un personaje protagonista de la historia, es siempre un buen arranque, y no cabe duda de que Diego Gelmírez (1070?-1140) no es sólo una de las figuras más célebres de la Edad Media gallega e hispana, sino una de las más fascinantes.

Resulta más que adecuado, por tanto, el hecho de que el comisario, Manuel Castiñeiras, y sus colaboradores hayan decidido centrarse en los viajes del célebre arzobispo para indicar que Compostela era, ya hace casi mil años, un importante centro urbano a nivel europeo a la vanguardia en tendencias culturales y receptora de las directrices artísticas más recientes mediante los extranjeros que la visitaban y los compostelanos que se trasladaban a Europa a través de los caminos de peregrinación que la comunicaban con el resto del continente. Un hecho que encuentra su paralelo más inmediato en las actuales rúas santiaguesas colmadas de turistas que llegan desde los mismos puntos de Europa que en el Medievo.

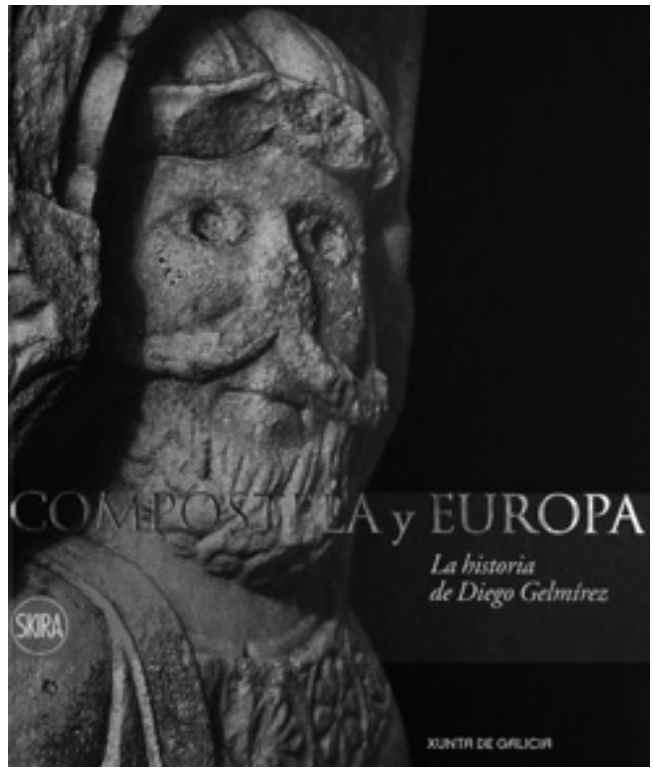

Es idóneo, asimismo, que la exposición se haya concebido de manera itinerante con una ruta que la ha conducido a París y Roma antes de recalar en Compostela, en una patente y pretendida analogía con los desplazamientos que llevaron al prelado en dos ocasiones a la capital italiana a través de Francia en 1100 y 1105. 
Ambos periplos estuvieron dominados por un objetivo eminentemente político, guiados por su constante empeño en dirigir a la sede jacobea primero al arzobispado, y luego a la distinción de metropolitana con privilegio de palio. De este modo, la muestra se articula alrededor de la vida de Diego Gelmírez y se centra en los ya mencionados viajes a Roma, y una pequeña travesía hasta Braga, en los que visitó algunos de los centros culturales, artísticos y políticos más poderosos del momento, evidenciando la importancia de las relaciones que el cabildo compostelano cimentó entonces.

Se trata de una exhibición modesta, con pocas piezas cuidadosamente escogidas en una espectacular puesta en escena, y con una gran apuesta por el apoyo audiovisual a las obras. Comienza trazando los orígenes de la familia del arzobispo, donde se señalan las estrechas relaciones que le unieron al cabildo compostelano dirigido por Diego Peláez desde su infancia, y termina con una serie de testimonios que indican la fascinación y la variedad en las apreciaciones que la singular figura de Gelmírez ha suscitado en autores pasados y contemporáneos. Entre estos dos términos, se revelan los vínculos de Compostela con Francia, Italia y Portugal, haciendo particular hincapié en las correspondencias artísticas que unieron estos territorios.

Destaca la variedad de los objetos mostrados, que van desde la escultura arquitectónica de capiteles y columnas, a una pila bautismal, altares portátiles, manuscritos o documentos, creaciones recogidas en diferentes rincones de Europa. La principal complicación derivada de la elección de un discurso expositivo tan ambicioso reside en la imposibilidad de trasladar a una sala de exposiciones las obras clave en el proceso de influencias internacionales que confluyeron en Compostela, como las grandes iglesias francesas del Camino de Santiago con sus monumentales portadas o el presbiterio vaticano, cuya combinación visual esclarecería verdaderamente la argumentación de la muestra. A falta de estas piezas, se han tenido que buscar aquellas creaciones disponibles para una exhibición itinerante, cuyos lazos resultan menos evidentes, o emplear copias de los originales. El apoyo de las producciones audiovisuales, con vídeos que incluyen algunos de los textos del catálogo, y reconstrucciones tridimensionales que materializan aquellas obras actualmente desaparecidas como la Porta Francigena o el Altar Mayor románico de la catedral compostelana resultan, así, fundamentales para que las intenciones de la muestra se hagan patentes en su amplia significación.

Es en el cuidado catálogo donde el discurso expositivo queda definido de una manera más precisa, con un conjunto de escritos de algunos de los más renombrados especialistas actuales en arte románico acompañado por un esmerado inventario de las obras con un admirable aparato gráfico e ilustrativas fichas. Los textos comienzan abordando el progreso de Compostela bajo el mandato de Diego Gelmírez desde múltiples puntos de vista aunque con el predominio del estudio histórico-artístico, para ponerlo en relación con los grandes centros culturales y de poder europeos, constatando finalmente cómo Santiago se constituyó bajo el mandato del arzobispo en uno de esos grandes núcleos. De este modo, la primera parte, compuesta por una serie de análisis sobre la Compostela románica, es complementada por la segunda, donde el desarrollo de la ciudad jacobea halla su contrapartida en algunas regiones ultrapirenaicas.

La apertura está a cargo del comisario, que inaugura el catálogo con una declaración de intenciones en la cual se justifica la elección de Diego Gelmírez como eje sobre el que pivotan la exposición y los escritos. El segundo de los textos de Manuel Castiñeiras dibuja una amplia perspectiva sobre la ciudad a finales del siglo XI y comienzos del XII, con observaciones acerca del mandato de Diego Peláez y un minucioso análisis de los avances de las obras en la catedral bajo su dirección y, sobre todo, la del arzobispo Gelmírez. Con ello, introduce muchos de los temas que van a desarrollar el resto de autores y que amplían esta visión del Santiago de Compostela medieval, de tal manera que se puede considerar como un capítulo que introduce y enmarca el resto de las aportaciones del catálogo.

Así, comienza incidiendo en el tema de la seductora personalidad de Diego Gelmírez y lo decisivo de su empeño en engrandecer la villa jacobea a través de la fábrica de su catedral. 
Este planteamiento encuentra su complemento en el texto de Ramón Villares, quien constata la repercusión del arzobispo en la fascinación que generaciones de gallegos han sentido por su figura, hasta desencadenar una intensa división de opiniones en la consideración de su influencia. Como ejemplo cita a escritores como Murguía u Otero Pedrayo, quienes lo aprecian como un gran gobernante que introdujo a Compostela en el panorama europeo, y otros como Benito Vicetto o Castelao, que lo juzgan responsable de la caída de Galicia y su separación de Portugal. Algunas de las obras más importantes escritas sobre el prelado en época contemporánea forman parte de la última sección de la muestra "A memoria escrita dun xenio" donde se exhiben libros de Anselm Gordon Biggs", Manuel Murguía², Ramón Otero Pedrayo ${ }^{3}$ o Richard A. Fletcher ${ }^{4}$.

En su relato, Manuel Castiñeiras se apoya sobre dos fuentes que serán también citadas en el resto de artículos del catálogo. Documentos esenciales en el estudio del episcopado de Gelmírez, quien posiblemente promovió su elaboración, y representadas en la muestra con la exposición de algunos de los manuscritos que las recogen, la Historia Compostellana relata las vicisitudes de la diócesis bajo su mandato, mientras que el Códice Calixtino es un compendio de cinco libros en los que se reúnen indicaciones para la liturgia jacobea, los milagros de Santiago, la leyenda del traslado de su cuerpo, la narración de la visita de Carlomagno a Compostela y la denominada "Guía del Peregrino". De este último se ocupan los textos de Klaus Herbers, quien desentraña su origen y estudia minuciosamente el texto y su difusión, y Alison Stones, que se encarga de analizar la ilustración del ejemplar más antiguo del Calixtino conservado, que se custodia en la catedral de Santiago.

El núcleo principal del capítulo redactado por el comisario consiste en una revisión de los avances en la edificación de la catedral compostelana en tiempos de Gelmírez, con un especial énfasis en los talleres escultóricos que trabajaron en sus capiteles. Para ello se hace eco de investigaciones clásicas como las de López Ferrei$\mathrm{ro}^{5}$, Arthur K. Porter ${ }^{6}$ o Kenneth J. Conant ${ }^{7}$, cuyos libros se exhiben en la exposición, combinándo- las con aportaciones contemporáneas como los concluyentes estudios de Serafín Moralejo8, y otras relecturas más modernas de la basílica.

La impresión final que suscita el panorama descrito de la catedral es la de un proyecto constructivo coherente y estructurado desde el inicio, centrado fundamentalmente en la condición de meta de peregrinación del templo, expresado a través del programa iconográfico y simbólico de su escultura, pero también de su conformación arquitectónica. Aunque este plan no se llevaría a la práctica, sí que se edificaron la parte de la cabecera que aún no había sido elevada en tiempos de Diego Peláez, y el transepto de la catedral, con obras clave como la magnificación del Altar Mayor, que es examinado por Miguel Taín a través de la reconstrucción de su configuración en época románica con las noticias que han llegado hasta hoy en día, fundamentalmente el informe redactado por Vega y Verdugo en el siglo XVIII. La otra gran creación gelmiriana es la construcción de dos portadas monumentales a ambos lados del transepto, minuciosamente diseccionadas por Castiñeiras y otros dos textos que actualizan las visiones tradicionales. Así, Francisco Prado-Vilar ofrece una relectura de la compleja iconografía de las columnas de la desaparecida portada norte, la denominada Porta Francigena, en clave mítica recurriendo a la epopeya de Ulises, mientras que Francisco Singul encuentra en la columna de fuste helicoidal de cruceiro de la parroquia de Santa María de Lamas en Boqueixón una posible pieza que formase parte de esa misma portada septentrional.

Los artículos del catálogo constatan la concentración en la catedral jacobea de una serie de influencias internacionales y aportaciones originales que van desde aspiraciones estéticas tomadas de las grandes basílicas francesas, hasta intenciones iconográficas derivadas de la influencia de la reforma eclesiástica promulgada por el Vaticano. Esta situación en la vanguardia cultural europea del momento, perceptible no sólo en la producción artística sino también literaria, habría sido inalcanzable sin la presencia en la ciudad de extranjeros y el traslado de compostelanos al exterior. De ello se ocupa Adeline Rucquoi, quien confirma el cosmopolitismo de la ciudad a comienzos del siglo XII. Además, casi 
todos los especialistas reunidos en el catálogo coinciden en destacar una serie de directrices básicas que subyacen a las manifestaciones culturales de la época examinadas, indistintamente de su procedencia. En primer lugar, en relación directa con Compostela, la importancia de los caminos de peregrinación como nexos de unión del continente y canalizadores de las energías creativas, hasta el punto que se ha llegado a crear el discutido concepto de "iglesias de peregrinación" bajo el que se engloban una serie de construcciones francesas y la propia basílica jacobea con innegables similitudes entre sí, noción de la que se ocupa John Williams. En segundo lugar, la autoridad de la reforma eclesiástica impulsada desde el Vaticano que cristalizaría en el uso de formas artísticas tomadas de la Antigüedad tardía como manera de demostrar la vuelta a los orígenes del cristianismo que se preconizaba. En este sentido, Arturo Carlo Quintavalle aventura una lista de posibles preceptos promulgados desde Roma, proponiendo que la impronta artística antigua no fue una consecuencia indirecta de las ideas de la reforma sino que el papado promulgó una serie de preceptos concretos a seguir.

El leitmotiv que atraviesa el discurso general de la exposición es el relato de los viajes del arzobispo jacobeo, fundamento que conecta en la muestra las obras de Compostela con las de otros grandes centros europeos con los que tuvo una vinculación directa, bien a través de sus talleres escultóricos, bien de nexos arquitectónicos, o bien por conexiones políticas. Los periplos de Gelmírez por tierras francesas han sido sintetizados en el capítulo de Jean-Marc Hofman y Annaig Chatain a través de las reproducciones de los grandes monumentos galos que presumiblemente visitó, expuestas en el Musée des Monuments Français en París. Destacan especialmente algunos de ellos, que son objeto de análisis en este catálogo. Saint-Sernin de Toulouse ha sido estudiado por Quitterie
Cazes, que no evita la problemática de la datación del edificio, además de señalar las evidentes semejanzas, ya apuntadas por Manuel Castiñeiras, entre sus portadas y las de Compostela. Cluny es explorado por José Luis Senra, estableciendo una relación entre el bloque occidental de su segunda iglesia con las galileas de algunos templos hispanos, y la posibilidad de que el proyecto catedralicio original de Gelmírez incluyese una estructura semejante. Las afinidades con Italia son señaladas por Rosa Vázquez, quien advierte el desarrollo de un creciente culto jacobeo en la península itálica durante el siglo XII. Por último, la visita del prelado compostelano a Braga, sin apenas influencia estética en la construcción del edificio catedralicio pero con gran incidencia en la importancia espiritual y política de Compostela, es analizada por José María Díaz Fernández.

En conclusión, cabe señalar lo apropiado de una propuesta expositiva de este carácter en año jacobeo, cuyo objetivo principal es demostrar el importante papel de Santiago de Compostela en la Europa medieval, alcanzado gracias a la tenacidad del arzobispo Gelmírez. La dificultad intrínseca a la intención de trasladar a una sala de exposiciones un discurso sobre las influencias recíprocas escultóricas y arquitectónicas de grandes edificios como la catedral compostelana, Saint-Sernin de Toulouse, Sainte-Foy de Conques y algunos monumentos italianos se ha conseguido salvar con el apoyo audiovisual. Sin embargo, es en el catálogo donde el objetivo verdaderamente se cumple, con un conjunto de escritos donde se conjugan minuciosos análisis artísticos con estudios históricos, que ponen de relieve la figura de Diego de Gelmírez y su importante papel en la consecución para la ciudad santiaguesa de un protagonismo central en el siglo XII europeo, no sólo desde el punto de vista del arte sino también de otras manifestaciones culturales y como notable núcleo político. 
NOTAS

* Beneficiaria del Programa FPU del Ministerio de Educación.

1 Anselm Gordon Biggs, Diego Gelmirez. First Archbishop of Compostela. A Dissertation, Washington, 1849.

2 Manuel Murguía, Don Diego Gelmírez, A Coruña, 1898.

${ }^{3}$ Ramón Otero Pedrayo, Gelmírez, o el genio afectuoso, creador $y$ humorista del tiempo románico. Vida y glosas de su vida, Santiago de Compostela, 1991.
${ }^{4}$ Richard A. Fletcher, Saint James's Catapult. The Life and Times of Diego Gelmirez of Santiago de Compostela, Oxford, 1984.

${ }^{5}$ El canónigo Antonio López Ferreiro publicó múltiples estudios acerca de varios aspectos históricoartísticos de la catedral de Santiago de Compostela, que se compendian en: Antonio López Ferreiro, Historia de la Santa A. M. Iglesia de Santiago de Compostela, Santiago de Compostela, 1898-1911.

6 Arthur Kingsley Porter, Romanesque Sculpture of the Pilgrimage Roads, Boston, 1923.
${ }^{7}$ Kenneth John Conant, The Early Architectural History of the Cathedral of Santiago de Compostela, Cambridge, 1926.

${ }^{8}$ Serafín Moralejo ha escrito gran variedad de artículos acerca de la catedral compostelana y sus avances en la Edad Media. Uno de sus escritos más destacados es su revisión de la obra de Kenneth J. Conant: Serafín Moralejo, "Notas para una revisión crítica de la obra de K. J. Conant", en: Kenneth John Conant, Arquitectura románica de la catedral de Santiago de Compostela, Santiago de Compostela, 1983. 